\title{
2020 American College of Rheumatology Guideline for the Management of Gout
}

John D. FitzGerald, ${ }^{1}$ (D) Nicola Dalbeth, ${ }^{2}$ (D) Ted Mikuls, ${ }^{3}$ (D) Romina Brignardello-Petersen, ${ }^{4}$ Gordon Guyatt, ${ }^{4}$ Aryeh M. Abeles, ${ }^{5}$ (D) Allan C. Gelber, ${ }^{6}$ (D) Leslie R. Harrold, ${ }^{7}$ Dinesh Khanna, ${ }^{8}$ (D) Charles King, ${ }^{9}$ Gerald Levy, ${ }^{10}$ Caryn Libbey, ${ }^{11}$ David Mount, ${ }^{12}$ Michael H. Pillinger, ${ }^{5}$ (D) Ann Rosenthal, ${ }^{13}$ Jasvinder A. Singh, ${ }^{14}$ (D)

James Edward Sims, ${ }^{15}$ Benjamin J. Smith, ${ }^{16}$ (D) Neil S. Wenger, ${ }^{17}$ Sangmee Sharon Bae, ${ }^{17}$ (iD Abhijeet Danve, ${ }^{18}$ Puja P. Khanna, ${ }^{19}$ Seoyoung C. Kim, ${ }^{20}$ (iD Aleksander Lenert, ${ }^{21}$ Samuel Poon, ${ }^{22}$ Anila Qasim, ${ }^{4}$ Shiv T. Sehra, ${ }^{23}$ Tarun Sudhir Kumar Sharma, ${ }^{24}$ Michael Toprover, ${ }^{5}$ Marat Turgunbaev, ${ }^{25}$ Linan Zeng, ${ }^{4}$ Mary Ann Zhang, ${ }^{20}$ (iD) Amy S. Turner, ${ }^{25}$ and Tuhina Neogi ${ }^{11}$ (D)

Guidelines and recommendations developed and/or endorsed by the American College of Rheumatology (ACR) are intended to provide guidance for particular patterns of practice and not to dictate the care of a particular patient. The ACR considers adherence to the recommendations within this guideline to be voluntary, with the ultimate determination regarding their application to be made by the physician in light of each patient's individual circumstances. Guidelines and recommendations are intended to promote beneficial or desirable outcomes but cannot guarantee any specific outcome. Guidelines and recommendations developed and endorsed by the ACR are subject to periodic revision as warranted by the evolution of medical knowledge, technology, and practice. ACR recommendations are not intended to dictate payment or insurance decisions, and drug formularies or other third-party analyses that cite ACR guidelines should state this. These recommendations cannot adequately convey all uncertainties and nuances of patient care.

The American College of Rheumatology is an independent, professional, medical and scientific society that does not guarantee, warrant, or endorse any commercial product or service.

Objective. To provide guidance for the management of gout, including indications for and optimal use of uratelowering therapy (ULT), treatment of gout flares, and lifestyle and other medication recommendations.

Methods. Fifty-seven population, intervention, comparator, and outcomes questions were developed, followed by a systematic literature review, including network meta-analyses with ratings of the available evidence according to the Grading of Recommendations Assessment, Development and Evaluation (GRADE) methodology, and patient input. A group consensus process was used to compose the final recommendations and grade their strength as strong or conditional.

Results. Forty-two recommendations (including 16 strong recommendations) were generated. Strong recommendations included initiation of ULT for all patients with tophaceous gout, radiographic damage due to gout, or frequent gout flares; allopurinol as the preferred first-line ULT, including for those with moderate-to-severe chronic kidney disease (CKD; stage $\geq 3$ ); using a low starting dose of allopurinol ( $\leq 100 \mathrm{mg} / \mathrm{day}$, and lower in CKD) or febuxostat ( $\leq 40 \mathrm{mg} /$ day); and a treat-to-target management strategy with ULT dose titration guided by serial serum urate (SU) measurements, with an SU target of $<6 \mathrm{mg} / \mathrm{dl}$. When initiating ULT, concomitant antiinflammatory prophylaxis therapy for a duration of at least 3-6 months was strongly recommended. For management of gout flares, colchicine, nonsteroidal antiinflammatory drugs, or glucocorticoids (oral, intraarticular, or intramuscular) were strongly recommended.

Conclusion. Using GRADE methodology and informed by a consensus process based on evidence from the current literature and patient preferences, this guideline provides direction for clinicians and patients making decisions on the management of gout.

This article is published simultaneously in Arthritis \& Rheumatology.

Supported by the American College of Rheumatology.

JJohn D. FitzGerald, MD, PhD: University of California, Los Angeles and VA Greater Los Angeles Health Care System, Los Angeles, California; ${ }^{2}$ Nicola
Dalbeth, MD, FRACP: University of Auckland, Auckland, New Zealand; ${ }^{3}$ Ted Mikuls, MD, MSPH: University of Nebraska Medical Center and VA NebraskaWestern lowa Health Care System, Omaha, Nebraska; ${ }^{4}$ Romina BrignardelloPetersen, DDS, MSc, PhD, Gordon Guyatt, MD, Anila Qasim, HBSc, MSc, 


\section{INTRODUCTION}

Gout is the most common form of inflammatory arthritis, affecting $~ 9.2$ million adults (3.9\%) in the US (1). While the etiology of gout is well-understood and there are effective and inexpensive medications to treat gout, gaps in quality of care persist (2-4). The 2012 American College of Rheumatology (ACR) Guidelines for the Management of Gout $(5,6)$ and other international specialty society guidelines recommend treatto-target strategies with use of urate-lowering therapy (ULT) (7-10). Despite these recommendations, over the past 2 decades there has been no increase in ULT utilization. Adherence to ULT remains poor $(2,11)$ and is the lowest adherence among treatments for 7 common chronic medical conditions (12). Complicating the efforts to improve adherence is the fact that the prior 2012 ACR Guidelines for the Management of Gout have been criticized due to low quality of evidence supporting treat-to-target recommendations $(13,14)$. Since the 2012 ACR Guidelines for the Management of Gout were published, several clinical trials have been conducted that provide additional evidence regarding the management of gout, leading the ACR Guidelines Subcommittee to determine that new guidelines were warranted.

\section{METHODS}

This guideline follows the ACR guideline development process (https://www.rheumatology.org/Practice-Quality/ClinicalSupport/Clinical-Practice-Guidelines) using the Grading of Recommendations Assessment, Development and Evaluation (GRADE) methodology to rate the certainty of evidence and develop recommendations (15-17), with an emphasis on developing actionable guidelines. ACR policy guided the management of

Linan Zeng, MD: McMaster University, Hamilton, Ontario, Canada; ${ }^{5}$ Aryeh M. Abeles, MD, Michael H. Pillinger, MD, Michael Toprover, MD: New York University School of Medicine, New York, New York; ${ }^{6}$ Allan C. Gelber, MD, MPH, PhD: Johns Hopkins University, Baltimore, Maryland; ${ }^{7}$ Leslie R. Harrold, MD: University of Massachusetts Medical School, Worcester Massachusetts, and Corrona, Waltham, Massachusetts; ${ }^{8}$ Dinesh Khanna, MD, MSc: University of Michigan, Ann Arbor; ${ }^{9}$ Charles King, MD: North Mississippi Medical Center, Tupelo; ${ }^{10}$ Gerald Levy, MD, MBA: Kaiser Permanente, Downey, California; ${ }^{11}$ Caryn Libbey, MD, Tuhina Neogi, MD, PhD, FRCPC: Boston University School of Medicine, Boston, Massachusetts; ${ }^{12}$ David Mount, MD: VA Boston Healthcare System, Boston, Massachusetts; ${ }^{13}$ Ann Rosenthal, MD: Medical College of Wisconsin, Milwaukee; ${ }^{14}$ Jasvinder A. Singh, MD, MPH: University of Alabama at Birmingham and Birmingham Veterans Affairs Medical Center, Birmingham, Alabama; ${ }^{15}$ James Edward Sims: Atlanta, Georgia; ${ }^{16}$ Benjamin J. Smith, DMSc, PA-C, DFAAPA: Florida State University College of Medicine School of Physician Assistant Practice, Tallahassee; ${ }^{17}$ Neil S. Wenger, MD, Sangmee Sharon Bae, MD: University of California, Los Angeles; ${ }^{18}$ Abhijeet Danve, MBBS, MD, FACP: Yale University, New Haven, Connecticut; ${ }^{19}$ Puja P. Khanna, MD, MPH: University of Michigan, VA Ann Arbor Healthcare System, Ann Arbor, Michigan; ${ }^{20}$ Seoyoung C. Kim, MD, ScD, MSCE, Mary Ann Zhang, MD: Brigham and Women's Hospital, Harvard Medical School, Boston, Massachusetts; ${ }^{21}$ Aleksander Lenert, MD, FRCPC: University of Kentucky, Lexington; ${ }^{22}$ Samuel Poon, MD: US Department of Veterans Affairs, Manchester, New Hampshire; ${ }^{23}$ Shiv T. Sehra, MD: Mount Auburn Hospital, Cambridge, Massachusetts; ${ }^{24}$ Tarun Sudhir Kumar Sharma, MD: Allegheny conflicts of interest and disclosures (https://www.rheumatology. org/Practice-Quality/Clinical-Support/Clinical-Practice-Guide lines/Gout). A full description of the methods is presented in Supplementary Appendix 1 (available on the Arthritis Care \& Research web site at http://onlinelibrary.wiley.com/doi/10.1002/acr.24180/ abstract).

Briefly, the Core Team, Expert Panel, and Voting Panel (consisting of rheumatologists, a general internist, a nephrologist, a physician assistant, and a patient representative) generated 57 population, intervention, comparator, and outcomes (PICO) questions to address the following: indications for ULT (5 questions), approaches to initiating ULT (7 questions), ongoing ULT management (18 questions), gout flares (10 questions), and lifestyle and other medication strategies in patients with gout (9 questions) and in individuals with asymptomatic hyperuricemia (8 questions). PICO questions were posted on the ACR web site for public comment (October 30-November 30, 2018) (for a list of team and panel members, see Supplementary Appendix 2, available on the Arthritis Care \& Research web site at http://onlinelibrary.wiley.com/doi/10.1002/acr.24180/ abstract). An in-person Patient Panel of 8 male patients with gout, moderated by one of the voting panel members (JAS), reviewed the evidence report (along with a summary and interpretation by the moderator) and provided patient perspectives and preferences.

The Core Team prespecified outcomes as critical or important for each PICO question for the systematic literature review. Outcomes varied across PICO topic (for details, see Supplementary Appendix 3, at http://onlinelibrary.wiley.com/ doi/10.1002/acr.24180/abstract). Gout flare and serum urate (SU) concentration (and tophus for PICO question 1) were specified as critical outcomes for all PICO questions specific to ULT. Pain was identified as critical for PICO questions specific

Health Network, Pittsburgh, Pennsylvania; ${ }^{25}$ Marat Turgunbaev, MD, MPH, Amy S. Turner: American College of Rheumatology, Atlanta, Georgia.

Dr. FitzGerald holds a patent for a lens-free microscope. Dr. Dalbeth has received consulting fees, speaking fees, and/or honoraria from Janssen, AbbVie, Dyve Biosciences, Arthrosi Therapeutics, Horizon, AstraZeneca, and Hengrui (less than $\$ 10,000$ each). Dr. Mikuls has received consulting fees from Pfizer (less than $\$ 10,000$ ) and research support from Horizon Therapeutics and Bristol-Myers Squibb. Dr. Harrold owns stock or stock options in Corrona. Dr. D. Khanna has received consulting fees, speaking fees, and/or honoraria from Horizon (less than $\$ 10,000$ ) and owns stock or stock options in Eicos Sciences. Dr. Mount has received consulting fees from Horizon Pharma (less than \$10,000). Dr. Pillinger has received research support from Hikma Pharmaceuticals and Horizon Pharma. Dr. Singh has received consulting fees, speaking fees, and/or honoraria from Crealta/ Horizon, Medisys, Fidia, UBM, Trio Health, Medscape, WebMD, Clinical Care Options, Clearview Healthcare Partners, Putnam Associates, Spherix, and Practice Point Communications (less than $\$ 10,000$ each) and owns stock or stock options in Amarin Pharmaceuticals and Viking Therapeutics. Dr. P. Khanna has received research support from Ironwood and Sobi. No other disclosures relevant to this article were reported.

Address correspondence to Tuhina Neogi, MD, PhD, FRCPC, 650 Albany Street, Suite X200, Evans Biomedical Research Center, Boston, MA 02118. E-mail: tneogi@bu.edu.

Submitted for publication December 10, 2019; accepted in revised form February 28, 2020. 
to gout flare. Gout flare was specified as the only critical outcome for management of lifestyle factors. All other outcomes were specified as important. Without standardized definitions for gout flare as an outcome (18), flare definitions varied by duration of follow-up in the various studies. Based on Patient Panel input, we specified that longer-term outcomes (e.g., 24 months) would be critical, while shorter durations (e.g., $\leq 12$ months) were considered important; it was recognized that very short time points (e.g., <6 months) may reflect the expected flares during ULT initiation.

We conducted systematic literature reviews (including 2 network meta-analyses [NMAs]) to address each PICO question (for search strategies and study selection process, see Supplementary Appendices 4 and 5, respectively, at http://online library.wiley.com/doi/10.1002/acr.24180/abstract). The first NMA evaluated the impact of starting ULT versus no ULT and the relative impact of the various ULT agents (for details, see Supplementary Appendix 6, available at http://onlinelibrary.wiley.com/ doi/10.1002/acr.24180/abstract). The second NMA evaluated antiinflammatory agents in gout flare management (for details, see Supplementary Appendix 7, available at http://onlinelibrary.wiley. com/doi/10.1002/acr.24180/abstract). To accomplish this second NMA, we grouped similar agents into nodes (e.g., acetic acid derivatives, profens, cyclooxygenase 2 agents, glucocorticoids, and interleukin-1 [IL-1] inhibitors).

The lowest level of evidence for the outcomes deemed critical to patients determined the certainty of evidence for each PICO question (15). For PICO questions specific to ULT, and on the basis of input from 1) the Patient Panel; 2) prior focus group work citing the importance of SU, gout flare, and tophi to patients (19); and 3) prior guidance from the GRADE working group (20), we made the following decisions. Where there was moderate or high certainty of evidence demonstrating improvement in any 1 of these 3 outcomes, we deemed this sufficient evidence to support a strong recommendation. The certainty of evidence from the other 2 outcomes was then designated as important but not critical to support the recommendation. The certainty of the evidence for each recommendation is presented in Tables 1-8, and the certainty of evidence for each outcome within each PICO question is in the full evidence report (see Supplementary Appendix 8, available on the Arthritis Care \& Research web site at http://onlinelibrary.wiley.com/doi/10.1002/ acr.24180/abstract).

Additionally, we report results using the more conservative rating of the evidence using the lowest level of evidence for any of the critical outcomes. Applying these more conservative rules, the summary certainty of evidence decreased (in comparison to the reported results) for some of the ULT recommendation statements, which would result in a lower strength of recommendation for 2 recommendations (PICO question 2: ULT indication for patients with erosions, and PICO question
27: switching to pegloticase for ULT failure). The details are available in the evidence report (Supplementary Appendix 8). Medication costs (not part of the systematic literature review), reported as average wholesale pricing as sourced from Lexicomp on August 23, 2019, were provided to the Voting Panel, as cost of treatment was included as part of the evaluation of risks and benefits of treatment medications (see Supplementary Appendix 9, available on the Arthritis Care \& Research web site at http://onlinelibrary.wiley.com/doi/10.1002/acr.24180/ abstract).

PICO questions were drafted into recommendation statements and were sent to the Voting Panel with the evidence report prior to round 1 voting. At a face-to-face meeting, the Voting Panel again reviewed draft recommendations, a summary of the voting results from round 1, the evidence report, and a summary of Patient Panel statements (1 patient from the Patient Panel [JES] and the Patient Panel moderator [JAS] attended the Voting Panel and were available to answer questions about the Patient Panel statements). To become a recommendation (for or against) in this guideline, at least $70 \%$ consensus of the Voting Panel was required.

The strength of each recommendation was rated as strong or conditional. Strong recommendations reflect decisions supported by moderate or high certainty of evidence where the benefits consistently outweigh the risks, and, with only rare exceptions, an informed patient and his or her provider would be expected to reach the same decision. Conditional recommendations reflect scenarios for which the benefits and risks may be more closely balanced and/or only low certainty of evidence or no data are available.

Recommendations in this guideline apply to patients with gout, except for a single recommendation regarding the use of ULT in individuals with asymptomatic hyperuricemia, which is defined as an SU concentration of $\geq 6.8 \mathrm{mg} / \mathrm{dl}$ with no prior gout flares or subcutaneous tophi. Patients with evidence of monosodium urate monohydrate (MSU) deposition on advanced imaging may still be considered asymptomatic if they have not had a prior gout flare or subcutaneous tophi.

These guidelines do not directly address the impact of gout or hyperuricemia on other comorbidities, such as cardiovascular disease (CVD), hypertension, urolithiasis, or chronic kidney disease (CKD). As we developed these guidelines for use by providers practicing in the US, we considered pharmacologic therapies available in the US, with select exceptions. Although lesinurad was withdrawn from the US market by the manufacturer during the course of guideline development, it remains Food and Drug Administration (FDA) approved, and we therefore considered the data in relation to relevant PICO questions. To facilitate the 2 NMAs, we also considered medications not available in the US to permit comparisons with other available medications in the network analysis. 


\section{RESULTS/RECOMMENDATIONS}

\section{Indications for pharmacologic ULT}

Initiating ULT is strongly recommended for gout patients with any of the following: $\geq 1$ subcutaneous tophi; evidence of radiographic damage (any modality) attributable to gout; OR frequent gout flares, with frequent being defined as $\geq 2$ annually.

From the ULT NMA (see Supplementary Appendix 6, available at http://onlinelibrary.wiley.com/doi/10.1002/acr.24180/ abstract) and randomized clinical trials (RCTs) of pegloticase (21-23) and lesinurad (24), there was high certainty of evidence regarding the efficacy of ULT in reducing flare frequency (23-26), tophi $(21,23)$, and SU concentrations (23-26). While many Patient Panel participants reported that they were initially hesitant to start ULT, after experiencing improved control of inflammatory symptoms and tophi, they became strong advocates for its earlier institution (for all indications for pharmacologic ULT, see Table 1 and Supplementary Figure 1, available at http://onlinelibrary.wiley. com/doi/10.1002/acr.24180/abstract).

Initiating ULT is conditionally recommended for patients who have previously experienced $>1$ flare but have infrequent flares (<2/year).

For patients with less frequent flares and no tophi, the potential clinical benefit of ULT would be lower than the ULT benefit for patients with more burdensome gout. In a single study (moderate certainty of evidence), patients with $\leq 2$ previous flares (and no more than 1 gout flare in the preceding year) randomized to receive febuxostat (versus placebo) were less likely to experience a subsequent flare (30\% versus $41 \%$; $P<0.05)(27)$.

Specific characteristics for patients with infrequent flares (e.g., SU concentration $>9 \mathrm{mg} / \mathrm{dl}, \mathrm{CKD}, \mathrm{CVD}$ ) that might influence the risk-benefit assessment were considered, but due to insufficient data for these subgroups, the Voting Panel did not find that these conditions warranted stronger ULT recommendations specific to these subgroups.

Initiating ULT is conditionally recommended against in patients with gout experiencing their first gout flare.

However, initiating ULT is conditionally recommended for patients with comorbid moderateto-severe CKD (stage $\geq 3$ ), SU concentration $>9 \mathrm{mg}$ / dl, or urolithiasis.

While conditionally recommending against ULT initiation following the first gout flare in a patient with "uncomplicated" gout, the Voting Panel considered Patient Panel input and recognized that there may be patients who would prefer (or benefit from) ULT, underscoring the need for shared decision-making. As noted above, data from the RCT of patients with $\leq 2$ previous flares (and no more than 1 gout flare in the preceding year) supported the benefit of ULT for reduction of SU concentration and gout flare risk (27). For patients with moderate-to-severe CKD (e.g., stage $\geq 3$ ), there is a higher likelihood of gout progression and development of clinical tophi (28-30). Furthermore, treatment options for gout flare are limited in this population, and there may be added benefit of using ULT to prevent progression of renal disease (31). Similarly, patients with markedly elevated SU concentrations (>9 mg/dl) are more likely to experience gout progression $(26,32)$. For patients with a history of urolithiasis, allopurinol and febuxostat provide benefit, as both medications lower 24-hour urinary uric acid excretion more than placebo (33). Among patients with calcium oxalate stones and hyperuricosuria, allopurinol ( $300 \mathrm{mg} /$ day) is superior to placebo in reducing the 3-year incidence of stone-related events (34).

Table 1. Indications for pharmacologic urate-lowering therapy (ULT)*

\begin{tabular}{|c|c|c|}
\hline Recommendation & $\begin{array}{l}\text { PICO } \\
\text { question }\end{array}$ & $\begin{array}{l}\text { Certainty of } \\
\text { evidence }\end{array}$ \\
\hline For patients with 1 or more subcutaneous tophi, we strongly recommend initiating ULT over no ULT. & 1 & High \\
\hline $\begin{array}{l}\text { For patients with radiographic damage (any modality) attributable to gout, we strongly recommend } \\
\text { initiating ULT over no ULT. }\end{array}$ & 2 & Moderate \\
\hline For patients with frequent gout flares ( $\geq 2 /$ year), we strongly recommend initiating ULT over no ULT. & 3 & High \\
\hline $\begin{array}{l}\text { For patients who have previously experienced }>1 \text { flare but have infrequent flares ( }<2 / \text { year), we conditionally } \\
\text { recommend initiating ULT over no ULT. }\end{array}$ & 4 & Moderate \\
\hline $\begin{array}{l}\text { For patients experiencing their first flare and CKD stage } \geq 3, S U>9 \mathrm{mg} / \mathrm{dl} \text {, or urolithiasis, we conditionally } \\
\text { recommend initiating ULT. }\end{array}$ & 5 & Very low \\
\hline $\begin{array}{l}\text { For patients with asymptomatic hyperuricemia (SU > } 6.8 \mathrm{mg} / \mathrm{dl} \text { with no prior gout flares or subcutaneous } \\
\text { tophi), we conditionally recommend against initiating any pharmacologic ULT (allopurinol, febuxostat, } \\
\text { probenecid) over initiation of pharmacologic ULT. }\end{array}$ & 57 & Hight \\
\hline
\end{tabular}

Strongly recommend Conditionally recommend Strongly recommend against Conditionally recommend against

* PICO = population, intervention, comparator, outcomes; CKD = chronic kidney disease; SU = serum urate.

† There is randomized clinical trial data to support the benefit that ULT lowers the proportion of patients who develop incident gout. However, based on the attributable risk, 24 patients would need to be treated for 3 years to prevent a single (incident) gout flare leading to the recommendation against initiating ULT in this patient group. 
Initiating ULT is conditionally recommended against in patients with asymptomatic hyperuricemia.

For patients with asymptomatic hyperuricemia, RCTs (designed to study CVD outcomes) demonstrated significant reduction in incident gout flares over 3 years. However, the development of incident gout was low for both ULT and placebo arms ( $<1 \%$ versus $5 \%)(35,36)$. In other words, 24 patients would need to be treated with ULT for 3 years to prevent a single (incident) gout flare. From observational studies, among patients with asymptomatic hyperuricemia with SU concentrations of $>9 \mathrm{mg} / \mathrm{dl}$, only $20 \%$ went on to develop gout within 5 years (32). The Voting Panel felt that, on average, for the majority of patients with asymptomatic hyperuricemia (including those with comorbid CKD, CVD, urolithiasis, or hypertension), the benefits of ULT would not outweigh potential treatment costs or risks for the large number of patients unlikely to progress to gout. This is also the case for patients with asymptomatic hyperuricemia with MSU crystal deposition as noted on imaging tests such as ultrasound or dual-energy computed tomography.

\section{Recommendations for choice of initial ULT for patients with gout}

Treatment with allopurinol as the preferred first-line agent, over all other ULTs, is strongly recommended for all patients, including those with moderate-to-severe CKD (stage $\geq 3$ ).

The Voting Panel strongly recommended allopurinol as the preferred first-line agent given its efficacy when dosed appropriately (often required doses $>300 \mathrm{mg} /$ day [37] up to the maximum FDAapproved dose of $800 \mathrm{mg} /$ day [38]), tolerability, safety, and lower cost. Using a lower starting dose mitigates safety issues specific to allopurinol hypersensitivity syndrome (AHS) $(39,40)$. The Voting Panel indicated that an optimal trial of oral medication would be appropriate prior to pegloticase due to cost differences and potential adverse effects of the latter medication (for recommendations for choice of initial ULT, see Table 2 and Supplementary Figure 2, available at http://onlinelibrary.wiley.com/doi/10.1002/ acr.24180/abstract).

The choice of either allopurinol or febuxostat over probenecid is strongly recommended for patients with moderate-to-severe CKD (stage $\geq 3$ ).

The choice of pegloticase as a first-line therapy is strongly recommended against.

Starting treatment with low-dose allopurinol ( $\leq 100 \mathrm{mg} /$ day and lower in patients with CKD [stage $\geq 3$ ]) and febuxostat ( $\leq 40 \mathrm{mg} / \mathrm{day}$ ) with subsequent dose titration over starting at a higher dose is strongly recommended.

Starting treatment with low-dose probenecid ( $500 \mathrm{mg}$ once to twice daily) with subsequent dose titration over starting at a higher dose is conditionally recommended.

A lower starting dose of any ULT reduces the risk of flare associated with initiation (41). The Patient Panel voiced a strong preference for safer ULT prescribing regimens through lower starting doses with subsequent dose escalation, even if such regimens required more blood draws and provider visits, over alternate regimens (e.g., starting with higher doses) that might incur more risk. Even lower initial allopurinol doses (e.g., $\leq 50 \mathrm{mg} /$ day)

Table 2. Recommendations for choice of initial urate-lowering therapy (ULT) in patients with gout*

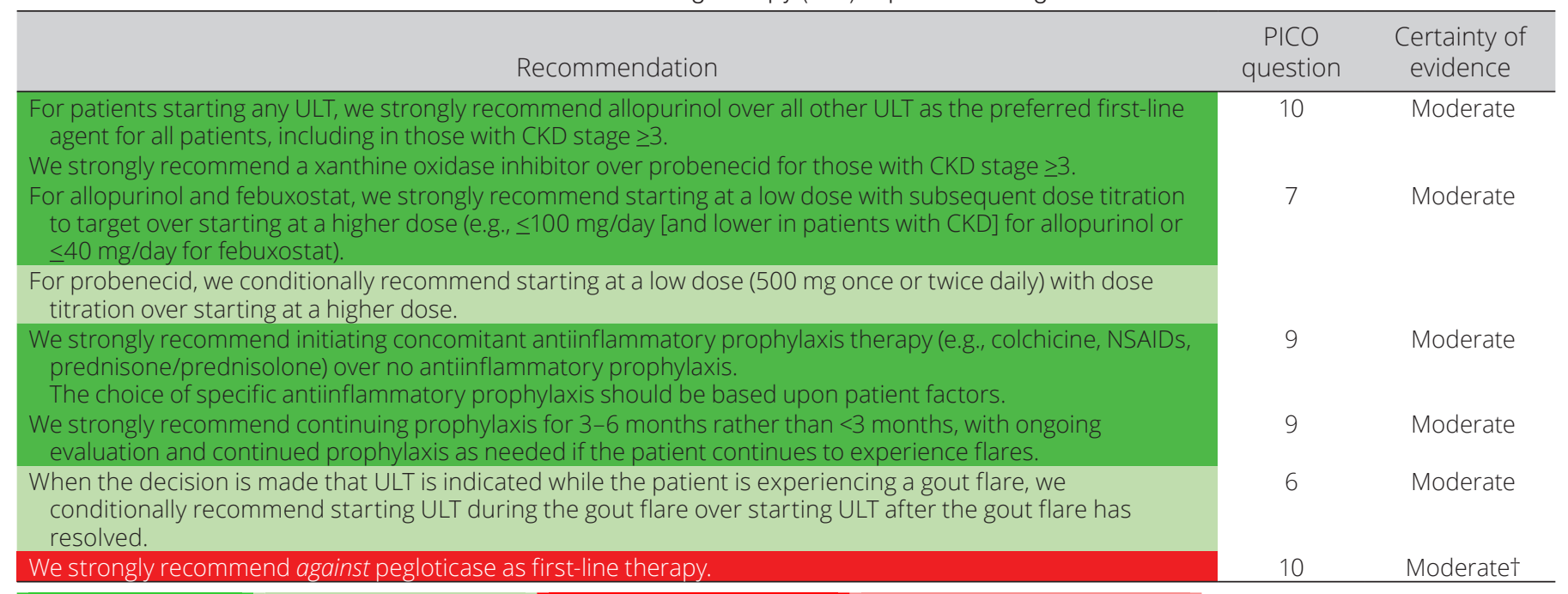

Strongly recommend Conditionally recommend Strongly recommend against Conditionally recommend against

* PICO = population, intervention, comparator, outcomes; CKD = chronic kidney disease; NSAIDs = nonsteroidal antiinflammatory drugs.

† Moderate evidence is in support of the efficacy of pegloticase, but due to cost, safety concerns, and favorable benefit-to-harm ratios of other untried treatment options, the recommendation is against using pegloticase as first-line agent. 
should be considered in patients with CKD. While higher starting doses and CKD are associated with risk of AHS (39), patients with CKD may still require dose titration above $300 \mathrm{mg} /$ day to achieve the SU target $(42,43)$. A population pharmacokineticpharmacodynamics study showed that larger body size and diuretic use indicated the need for higher allopurinol doses to achieve greater urate reduction. Worse renal function only had a modest negative impact on urate reduction (44). Other studies have demonstrated that allopurinol dose escalation can be done safely in this population $(40,45)$.

Administering concomitant antiinflammatory prophylaxis therapy (e.g., colchicine, nonsteroidal antiinflammatory drugs [NSAIDs], prednisone/ prednisolone) over no antiinflammatory prophylaxis therapy is strongly recommended.

Based on 8 RCTs $(41,46-52)$ and 2 observational studies $(53,54)$, there is moderate certainty of evidence to support the strong recommendations to use antiinflammatory prophylaxis therapy when initiating ULT. Continuation of prophylaxis for at least 3-6 months after ULT initiation was recommended because shorter durations were associated with flares upon cessation of prophylaxis $(55,56)$. After cessation, monitoring for flare activity and continuation of antiinflammatory treatment as needed if the patient continues to experience flares was recommended.

Continuing concomitant antiinflammatory prophylaxis therapy for 3-6 months over <3 months, with ongoing evaluation and continued prophylaxis as needed if the patient continues to experience gout flares, is strongly recommended.

\section{Timing of ULT initiation}

When the decision is made that ULT is indicated while the patient is experiencing a gout flare, starting ULT during the gout flare over starting ULT after the gout flare has resolved is conditionally recommended.

Starting ULT during a flare has conceptual benefits, including the time efficiency offered by initiating therapy during the concurrent flare visit rather than risking the patient not returning for ULT initiation. Furthermore, input from the Patient Panel emphasized that patients are likely to be highly motivated to take ULT due to the symptoms related to the current flare. However, concerns about starting ULT during a flare include potential extension or worsening of a flare, as well as the possibility of information overload for patients, which may lead to conflating flare management and long-term ULT. Two small RCTs $(57,58)$ and an observational study (59) support the hypothesis that starting ULT during a flare does not significantly extend flare duration or severity. Input from the Patient Panel, citing their own ability to simultaneously process information related to flare treatment and ULT initiation together, along with their preference to start on a treatment path sooner to prevent future flares, influenced the final recommendation. As with all conditional recommendations, there may be patient factors or preferences that would reasonably support the alternative of delaying ULT initiation until the flare has resolved.

A treat-to-target management strategy that includes ULT dose titration and subsequent dosing guided by serial SU measurements to achieve a target SU, over a fixed-dose ULT strategy, is strongly recommended for all patients receiving ULT.

Achieving and maintaining an SU target of $<6$ $\mathrm{mg} / \mathrm{dl}$ over the use of no target is strongly recommended for all patients receiving ULT.

We recommend using a treat-to-target management strategy to optimize patient outcomes by achieving and maintaining an SU target of $<6 \mathrm{mg} / \mathrm{dl}$ rather than using a fixed-dose strategy (Table 3 and Supplementary Figure 2, available at http://onlinelibrary.wiley. com/doi/10.1002/acr.24180/abstract). There is moderate- and high-quality evidence supporting these 2 recommendations. In an RCT from the UK (43), patients randomized to a nurse-led, treatto-target protocol demonstrated greater ULT adherence, lower SU concentrations, reduction in tophi, and a lower proportion of frequent $(\geq 2)$ gout flares at 24 months, compared with patients randomized to general practitioner-led usual care (an approach more often characterized by a fixed-dose strategy when ULT is administered). Two separate pharmacist-led interventions in the US, both incorporating treat-to-target strategies, were superior to usual care in terms of treatment adherence, SU outcomes, and higher allopurinol dosing $(60,61)$. Additional studies provide support for ULT dose escalation to achieve target SU levels, including dose titration of allopurinol in patients with CKD $(40,43)$. While a specific dose titration schedule is left to provider and patient to individualize based on patient comorbidities and preferences, ULT titration should occur over a reasonable time frame (e.g., weeks to months, not years) to prevent "treatment inertia" (62). In contrast to the 2012 ACR Guidelines for the Management of Gout, due to lack of supporting evidence for additional specific thresholds, we do not define further thresholds for patients warranting more intensive ULT.

Delivery of an augmented protocol of ULT dose management by nonphysician providers to optimize the treat-to-target strategy that includes patient education, shared decision-making, and treat-to-target protocol is conditionally recommended for all patients receiving ULT.

Based on recent nurse- $(43)$ and pharmacist-led $(60,61)$ interventions, the Voting Panel supported the benefit of an augmented delivery-of-care using patient education and shared decisionmaking through implementation of a treat-to-target protocol over 
Table 3. Recommendations for all patients taking urate-lowering therapy (ULT)*

\begin{tabular}{|c|c|c|}
\hline Recommendation & $\begin{array}{l}\text { PICO } \\
\text { question }\end{array}$ & $\begin{array}{l}\text { Certainty of } \\
\text { evidence }\end{array}$ \\
\hline $\begin{array}{l}\text { For all patients taking ULT, we strongly recommend a treat-to-target strategy of ULT dose management that } \\
\text { includes dose titration and subsequent dosing guided by serial SU values to achieve an SU target over a } \\
\text { fixed, standard-dose ULT strategy. }\end{array}$ & 13 & Moderate \\
\hline $\begin{array}{l}\text { For all patients taking ULT, we strongly recommend continuing ULT to achieve and maintain an SU target of }<6 \\
\text { mg/dl over no target. }\end{array}$ & 14 & High \\
\hline $\begin{array}{l}\text { For all patients taking ULT, we conditionally recommend delivery of an augmented protocol of ULT dose } \\
\text { management by nonphysician providers to optimize the treat-to-target strategy that includes patient } \\
\text { education, shared decision-making, and treat-to-target protocol. }\end{array}$ & 8 & Moderate \\
\hline We conditionally recommend continuing ULT indefinitely over stopping ULT. & 19 & Very low \\
\hline
\end{tabular}

Strongly recommend Conditionally recommend Strongly recommend against Conditionally recommend against

* PICO = population, intervention, comparator, outcomes; SU = serum urate.

usual care. However, the panel recognized that these resources may not be available in all health care settings, and that the key is for the treating provider (who could be the treating physician) to educate the patient and implement a treat-to-target protocol.

\section{Duration of ULT}

Continuing ULT indefinitely over stopping ULT is conditionally recommended.

For patients in clinical remission taking ULT (e.g., no flares for $\geq 1$ year and no tophi [63]), the Voting Panel considered ULT cessation or tapering. In a single case series where ULT was withheld in patients in clinical remission with years of wellcontrolled SU concentrations prior to cessation, only $13 \%$ of patients (27 of 211) whose SU concentration remained at $<7 \mathrm{mg} / \mathrm{dl}$ while not receiving ULT had no flares during a 5-year follow-up period. Furthermore, patients with higher SU concentrations after withholding therapy had more frequent flares with greater likelihood of flares associated with higher SU levels (37). The Patient Panel voiced concerns about a return or worsening of gout symptoms, tophi, or joint damage with ULT cessation. If therapy is well-tolerated and not burdensome, the Patient Panel expressed a preference to continue treatment.

\section{Recommendations for patients receiving ULT medications}

\section{Allopurinol}

Testing for the HLA-B*5801 allele prior to starting allopurinol is conditionally recommended for patients of Southeast Asian descent (e.g., Han Chinese, Korean, Thai) and for African American patients, over not testing for the HLA-B $\$ 5801$ allele.

Universal testing for the HLA-B*5801 allele prior to starting allopurinol is conditionally recommended against in patients of other ethnic or racial background over testing for the HLA-B*5801 allele.

As noted above, starting allopurinol in daily doses of $\leq 100 \mathrm{mg}$ (and lower doses in patients with (KD) is strongly recommended over starting at a higher dose.

The HLA-B*5801 allele is associated with a markedly elevated risk for AHS $(64,65)$. The prevalence of HLA-B*5801 is highest among persons of Han Chinese, Korean, and Thai

Table 4. Recommendations for patients taking specific urate-lowering therapy (ULT) medications*

\begin{tabular}{|c|c|c|}
\hline Recommendation & $\begin{array}{c}\text { PICO } \\
\text { question }\end{array}$ & $\begin{array}{c}\text { Certainty of } \\
\text { evidence }\end{array}$ \\
\hline \multicolumn{3}{|l|}{ Allopurinol } \\
\hline \multicolumn{3}{|l|}{ We conditionally recommend against HLA-B*5801 testing in all others. } \\
\hline $\begin{array}{l}\text { For patients with a prior allergic response to allopurinol who cannot be treated with other oral ULT, we } \\
\text { conditionally recommend using allopurinol desensitization. }\end{array}$ & 23 & Very low \\
\hline $\begin{array}{l}\text { For patients with gout taking febuxostat with a history of CVD or a new CV event, we conditionally recommend } \\
\text { switching to an alternative ULT agent if available and consistent with other recommendations in this guideline. }\end{array}$ & 22 & Moderate \\
\hline \multicolumn{3}{|l|}{ Uricosurics } \\
\hline $\begin{array}{l}\text { For patients considered for, or taking uricosuric treatment, prior to starting any uricosuric treatment, we } \\
\text { conditionally recommend against checking urinary uric acid over checking urinary uric acid. }\end{array}$ & 28 & Very low \\
\hline For patients taking uricosuric treatment, we conditionally recommend against alkalinizing urine. & 29 & Very low \\
\hline
\end{tabular}


descent (7.4\%) (66), lower among African Americans (3.8\%), and even lower among whites and Hispanics (0.7\% each) (66). Testing for this allele among Asians and African American patients was reported to be cost-effective (incremental cost-effectiveness ratios $<\$ 109,000$ per quality-adjusted life years) (67). Asian and African American patients taking allopurinol both have a 3-fold increased risk of AHS compared with white patients taking allopurinol (68) (for recommendations for ULT medications, see Table 4 and Supplementary Figure 3, available at http://onlinelibrary.wiley.com/doi/10.1002/acr.24180/abstract).

Allopurinol desensitization is conditionally recommended for patients with a prior allergic response to allopurinol who cannot be treated with other oral ULT agents.

The level of evidence supporting this recommendation was very low $(69,70)$. The Voting Panel recognized that desensitization protocols $(69,70)$ are not commonly used, with the majority of currently practicing rheumatologists having limited experience in these protocols.

\section{Febuxostat}

Switching to an alternative oral ULT agent, if available and consistent with other recommendations in this guideline, is conditionally recommended for patients taking febuxostat with a history of CVD or a new CVD-related event.

At the Voting Panel meeting, there was much discussion about the data, Patient Panel input, and interest to provide recommendations consistent with the FDA black box warning for febuxostat (71). The Voting Panel considered data from the CARES RCT (72) and 2 observational studies $(73,74)$. In the FDA-mandated CARES trial of febuxostat versus allopurinol (72), there was no difference between the 2 arms in the primary composite CVD end point. Febuxostat, however, was associated with a higher risk of CVD-related death and all-cause mortality (driven by CVD deaths) compared with allopurinol, but there was no association with the other 3 secondary CVD outcomes (nonfatal myocardial infarction, nonfatal stroke, or urgent revascularization for unstable angina). Interpretation of these results is complicated by a high dropout rate with a majority of deaths occurring after ULT discontinuation (72). Moreover, the lack of an untreated control group means the absolute CVD risk related to febuxostat is unknown. A large observational study (recruitment not selected for CVD) did not show an increased risk of CVD or all-cause mortality associated with febuxostat initiation compared with allopurinol using methods to address confounding by indication (73). Another study using a managed care database demonstrated lower risk of any major CVD event among febuxostat initiators than allopurinol initiators, though confounding by indication may not have been adequately addressed (74). The
Patient Panel representative stated members would be willing to accept "some" incremental CVD risk as long as the treatment adequately controlled their gout. Thus, as for many such decisions with conditional recommendations, providers and patients should engage in shared decision-making when considering febuxostat for patients at high risk for CVD.

\section{Uricosurics}

Checking urinary uric acid is conditionally recommend against for patients considered for or receiving uricosuric treatment.

Alkalinizing the urine is conditionally recommended against for patients receiving uricosuric treatment.

A single observational study demonstrated that higher levels of 24-hour urinary uric acid and higher levels of undissociated urinary uric acid were associated with urolithiasis (75). However, the Voting Panel indicated that the challenges with 24-hour urine collection or nomogram-based testing, which can both be affected by diet, negate the utility of such testing in light of a very low level of evidence.

We found no evidence to support a recommendation of checking urinary uric acid level for patients receiving uricosuric treatment or for alkalinizing the urine. The Voting Panel supported standard best practice that patients with known renal calculi or moderate-to-severe CKD (stage $\geq 3$ ) should not be treated with uricosurics. For patients who are treated with uricosurics, patients should receive counseling about adequate hydration, but they need not be prescribed alkalinizing agents given the lack of evidence for efficacy.

As use of uricosurics remains infrequent, we did not formally vote on indications for uricosuric medications. However, we concur with the 2012 ACR Guidelines for the Management of Gout that add-on therapy to partially responsive xanthine oxidase inhibitor (XOI) treatment can result in improved SU control $(24,25,76)$.

\section{When to consider changing ULT strategy}

Switching to a second XOI over adding a uricosuric agent is conditionally recommended for patients taking their first XOI, who have persistently high SU concentrations (>6 mg/dl) despite maximum-tolerated or FDA-indicated XOI dose, and who have continued frequent gout flares (>2 flares/year) OR who have nonresolving subcutaneous tophi.

Several lesinurad studies demonstrated the benefit of adding a uricosuric medication to $\mathrm{XOI}$ treatment $(25,76)$. However, we found no studies directly addressing the choice in the above 
PICO question, resulting in the conditional recommendation to switch to a second $\mathrm{XOI}$ after the first $\mathrm{XOI}$ failure (for recommendations for consideration of changing ULT strategy, see Table 5 and Supplementary Figure 2, available at http://onlinelibrary.wiley.com/ doi/10.1002/acr.24180/abstract).

Switching to pegloticase over continuing current ULT is strongly recommended for patients with gout for whom XOI treatment, uricosurics, and other interventions have failed to achieve the SU target, and who continue to have frequent gout flares ( $\geq 2$ flares/year) OR who have nonresolving subcutaneous tophi.

Switching to pegloticase over continuing current ULT is strongly recommended against for patients with gout for whom XOI treatment, uricosurics, and other interventions have failed to achieve the SU target, but who have infrequent gout flares ( $<2$ flares/year) AND no tophi.

In clinical trials, patients with 3 or more self-reported gout flares during the previous 18 months, $\geq 1$ tophi, and gouty arthropathy, defined clinically or radiographically as joint damage due to gout, were randomly assigned to pegloticase treatment. Patients additionally had contraindication to treatment with allopurinol or history of treatment failure to normalize uric acid despite $\geq 3$ months of treatment with the maximum medically appropriate allopurinol dose (determined by the treating physician). For these patients with frequent gout flares or nonresolving subcutaneous tophi, clinical trials demonstrated improved SU concentrations, low frequency of flares (77), reduction in tophi (21), and improved quality of life (22) among those receiving pegloticase. However, these outcomes come with high costs, twice-monthly infusions, and the potential for serious allergic reactions. For patients with infrequent gout flares and no tophi, we would expect a similar benefit in SU reduction. For patients with only infrequent flares, the magnitude of benefit would be substantially smaller than for patients with frequent flares, and there would be no benefit in reduction of tophi when no tophi are present. The harms and costs of administering pegloticase would likely be similar in patients with mild versus severe disease, resulting in limited benefit and appreciable harm along with very high costs, leading the panel to conclude that the costs and harms clearly outweigh the benefits. This conclusion, along with strong Patient Panel statements about not wanting to receive twice-monthly infusions to prevent infrequent gout flares, resulted in the strong recommendation against using pegloticase for patients with mild disease.

The above scenarios represent extremes of gout clinical severity resulting in strong "for" and "against" recommendations. The Voting Panel considered intermediary scenarios, but given the potential variability, the panel opted to simply defer to provider judgment balanced with patient preferences, regarding the optimal treatment strategy for individuals not described above. To clarify, as outlined above, there is a strong recommendation to follow a treat-to-target management strategy for all patients receiving ULT. However, the recommendation for treat-to-target strategy is not absolute and not meant to be pursued at "any cost." Even strong recommendations require sound clinical judgment to balance the potential clinical benefits and harms (including costs) of medical decisions (78).

\section{Gout flare management}

Using colchicine, NSAIDs, or glucocorticoids (oral, intraarticular, or intramuscular) as appropriate firstline therapy for gout flares over IL-1 inhibitors or adrenocorticotropic hormone (ACTH) is strongly recommended for patients experiencing a gout flare.

Given similar efficacy and a lower risk of adverse effects, low-dose colchicine over high-dose colchicine is strongly recommended when colchicine is the chosen agent.

Table 5. When to consider switching to a new urate-lowering therapy (ULT) strategy*

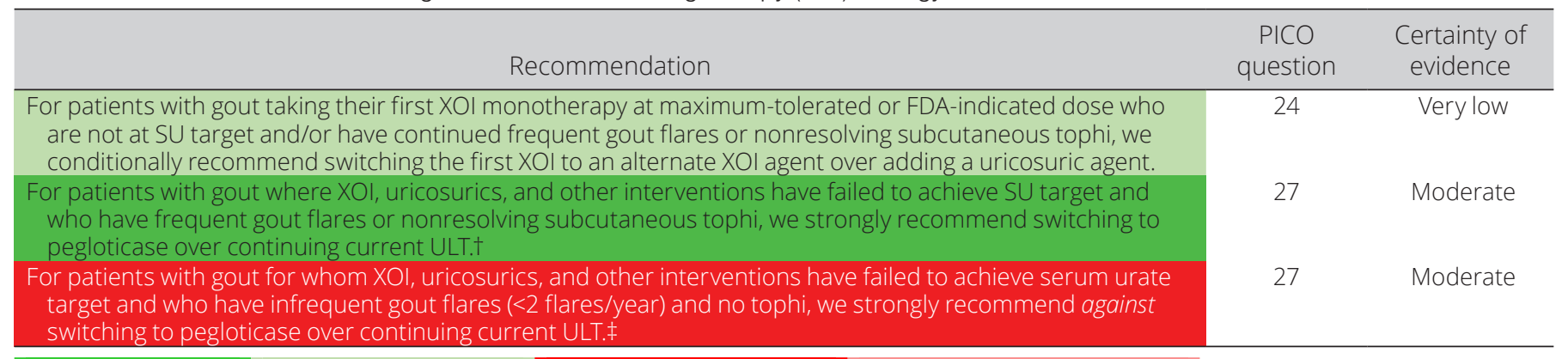


Using topical ice as an adjuvant treatment over no adjuvant treatment is conditionally recommended for patients experiencing a gout flare.

Using an IL-1 inhibitor over no therapy (beyond supportive/analgesic treatment) is conditionally recommended for patients experiencing a gout flare for whom the above antiinflammatory therapies are either ineffective, poorly tolerated, or contraindicated.

Treatment with glucocorticoids (intramuscular, intravenous, or intraarticular) over IL-1 inhibitors or ACTH is strongly recommended for patients who are unable to take oral medications.

The Voting Panel's recommendation of colchicine, NSAIDs, or glucocorticoids as preferred first-line therapies was based on substantial trial data demonstrating efficacy, relative low cost (versus IL-1 inhibitors and ACTH), and tolerability of these agents in flare management, particularly when administered early after symptom onset. Appropriate dosing and duration should be guided by the severity of the flare. For colchicine specifically, the FDA-approved dosing should be followed (1.2 mg immediately followed by $0.6 \mathrm{mg}$ an hour later, with ongoing antiinflammatory therapy until the flare resolves). Based on similar efficacy between agents demonstrated in the NMA (79-88), the Voting Panel did not further prioritize between the first-line agents, noting that treatment selection should be driven by patient factors (e.g., comorbidity, access, past experience) as part of shared decisionmaking. Likewise, parenteral glucocorticoids were favored over alternative agents when oral dosing is not possible. In patients experiencing an inadequate response to an initial agent, the Voting Panel cited insufficient evidence to make specific recommendations regarding subsequent antiinflammatory agents to use. If a patient is unable to tolerate or has contraindications to any of the other conventional alternatives, the Voting Panel conditionally recommended the use of IL-1 inhibitors (84,88-90), recognizing concerns over patient access due to cost. Noting limited supporting data (91), the Voting Panel recommended the use of topical ice as an adjuvant therapy for flares.

Underscoring the importance of optimal flare management, the Patient Panel emphasized its preference for early intervention given the challenges of engaging a provider in timely manner, including an at-home "medication-in-pocket" strategy for patients who are able to identify the early signs of flare onset. In the absence of "rapid" access to an effective oral medication, the Patient Panel also indicated its preference for an injectable therapy in appropriate circumstances to achieve pain relief as quickly as possible (for all recommendations for gout flare managment, see Table 6 and Supplementary Figure 4, available at http://online library.wiley.com/doi/10.1002/acr.24180/abstract).

\section{Management of lifestyle factors}

Limiting alcohol intake is conditionally recommended for patients with gout, regardless of disease activity.

Limiting purine intake is conditionally recommended for patients with gout, regardless of disease activity.

Limiting high-fructose corn syrup intake is conditionally recommended for patients with gout, regardless of disease activity.

Using a weight loss program (no specific program endorsed) is conditionally recommended for those patients with gout who are overweight/ obese, regardless of disease activity.

Table 6. Gout flare management*

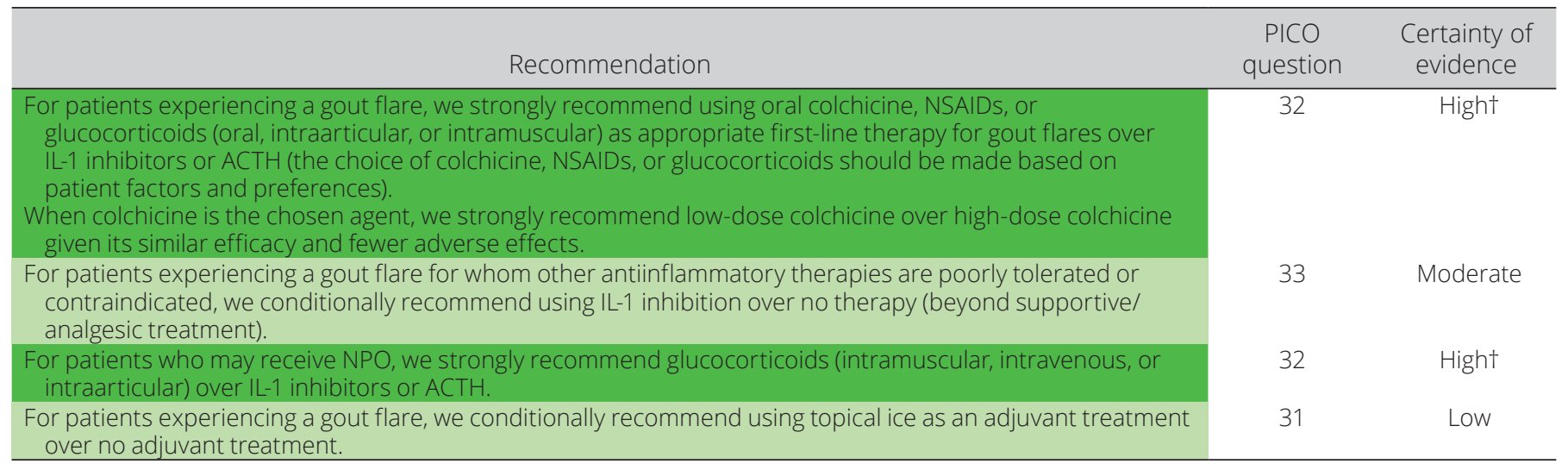

Strongly recommend Conditionally recommend Strongly recommend against Conditionally recommend against

* $\mathrm{PICO}=$ population, intervention, comparator, outcomes; NSAIDs = nonsteroidal antiinflammatory drugs; IL-1 = interleukin-1; ACTH = adrenocorticotropic hormone; NPO = nothing by mouth (nulla per os).

$\dagger$ High quality of evidence from network meta-analyses supporting canakinumab, which has superior mean pain score reduction and mean day-2 joint tenderness reduction. However, the Voting Panel raised concern that the comparator was weak (triamcinolone $40 \mathrm{mg}$ ) and that cost issues significantly favor other agents. 


\section{Adding vitamin C supplementation is condi- tionally recommended against for patients with gout, regardless of disease activity.}

The Voting Panel discussed data demonstrating the important genetic contributions to the development and severity of hyperuricemia and gout $(92,93)$ and informally recommended that providers be mindful when soliciting information regarding the dietary habits of patients and ensure that discussions regarding dietary recommendations are not misinterpreted as "patientblaming," as patients frequently feel stigmatized when discussing gout with their providers (94). Dietary modifications likely yield only small changes in SU concentration, but dietary factors may serve as triggers for flares, and patients frequently seek advice on dietary management (for recommendations for management of lifestyle factors, see Table 7 and Supplementary Figure 5, available at http://onlinelibrary.wiley.com/doi/10.1002/acr.24180/abstract).

Alcohol. SU levels among patients who limited or abstained from alcohol were $1.6 \mathrm{mg} / \mathrm{dl}$ lower compared with patients who did not do so $(95,96)$. Results from a recent diet and genetics meta-analysis that was noted above (92) demonstrated that the impact of diet or individual food items on SU concentration was small. As an example, a unit of beer raised SU concentrations by $0.16 \mathrm{mg} / \mathrm{dl}$. The effects of a healthy diet, Mediterranean diet, or Dietary Approaches to Stop Hypertension (DASH) diet were even smaller (92).

In a case-crossover study, consuming $>1-2$ alcoholic beverage servings in the prior 24 hours was associated with a $40 \%$ higher risk of gout flare than periods without alcohol consumption, with a dose-response relationship (97). A small cohort study demonstrated that despite receiving ULT, heavy drinkers ( $\geq 30$ units of alcohol/week) were more likely to continue having gout flares compared with those who do did not drink heavily (95).

Low purine diet. From the same case-crossover study noted above, there was a dose-response relationship between increasing purine intake and risk of gout flare (98). However, a small RCT ( $n=29$, with all participants receiving ULT with SU at target at the start of trial) using an educational intervention focused on low purine intake did not demonstrate lower SU concentrations compared with usual diet, despite significant improvements in patient dietary knowledge (99).

High-fructose corn syrup. The ingestion of $1 \mathrm{gm}$ of fructose/kg of body weight increases SU concentration by 1-2 $\mathrm{mg} / \mathrm{dl}$ within 2 hours of ingestion (100). In the National Health and Nutrition Examination Survey, artificially sweetened carbonated beverage consumption was associated with higher SU levels (101). In the Nurses' Health Study, greater consumption of highfructose corn syrup was associated with higher risk of incident gout (102). However, there were no data focused on patients with existing gout.

Weight loss. The Voting Panel considered the impact of weight loss and specific dietary programs (including the DASH diet [103]). Due to small sample sizes, studies of patients without gout (or not defined), and risk of bias assessments, the certainty of the evidence was rated as very low for both SU and flares. Several studies and a systematic literature review (104) addressed weight loss approaches either directly $(96,105)$ or indirectly (e.g., bariatric surgery [106,107], or dietary advice [108]). In a small cohort $(n=11)$ of obese patients, a mean weight loss of $5 \mathrm{~kg}$ resulted in a mean SU lowering of $1.1 \mathrm{mg} /$ dl (96). In a large cohort study, obesity was associated with a higher risk of incident gout, but not recurrent gout flares (105). However, changes in body mass index (BMI) over time were associated with the risk of recurrent gout flare. An increase in $\mathrm{BMI}$ of $>5 \%$ was associated with $60 \%$ higher odds of recurrent flare, and a decrease in BMl of $>5 \%$ was associated with $40 \%$ lower odds of recurrent flare compared with those without weight change $(-3.5 \% \leq \mathrm{BMl} \leq 3.5 \%)$ (105). A small study of 12 patients undergoing bariatric surgery (mean $34.3 \mathrm{~kg}$ weight loss over 12 months) demonstrated a mean SU reduction of $2.0 \mathrm{mg} /$ dl (106). Likewise, gout patients losing weight through bariatric surgery or diet experienced reduced flare frequency (108), although patients undergoing bariatric surgery may actually have

Table 7. Management of lifestyle factors*

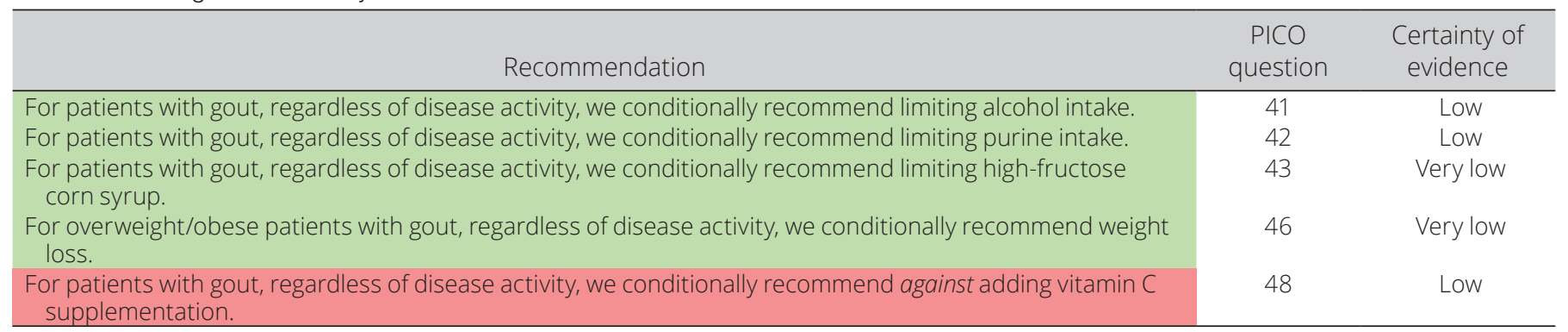

Strongly recommend Conditionally recommend Strongly recommend against Conditionally recommend against

* PICO = population, intervention, comparator, outcomes. 
a transient increase in flares risk during the first postoperative month (106).

Other dietary recommendations. The Voting Panel reviewed the data for cherries/cherry extract and dairy protein. The certainty of evidence drawn mainly from observational studies was low or very low, precluding specific recommendations on these topics. The Voting Panel reached consensus that data on vitamin $\mathrm{C}$ were insufficient to support continued recommendation for its use in patients with gout. Two small RCTs $(n=29$ and $n=$ 40) showed clinically insignificant changes in SU concentrations for patients with gout taking vitamin C $(99,109)$.

\section{Management of concurrent medications}

Switching hydrochlorothiazide to an alternate antihypertensive when feasible is conditionally recommended for patients with gout, regardless of disease activity.

Choosing losartan preferentially as an antihypertensive agent when feasible is conditionally recommended for patients with gout, regardless of disease activity.

Stopping low-dose aspirin (for patients taking this medication for appropriate indications) is conditionally recommended against for patients with gout, regardless of disease activity.

Adding or switching cholesterol-lowering agents to fenofibrate is conditionally recommended against for patients with gout, regardless of disease activity.

Medications noted above are known to have effects on SU concentrations (110). The Voting Panel made recommendations specific to hydrochlorothiazide and losartan (111) in clinical scenarios where such changes are feasible. Switching, stopping, or adding a medication should only be considered when the potential SU concentration/gout benefits exceed the potential risks or harms of the medication change.

Recognizing that there are few practical alternatives to lowdose aspirin, the Voting Panel specifically recommended against its cessation as a means of SU reduction when a patient is taking it for an appropriate indication. Likewise, the Voting Panel specifically recommended against adding or switching cholesterollowering agents (e.g., statins, bile acid sequestrants, nicotinic acid agents, etc.) to fenofibrate despite its urate-lowering effects (112), as the risks, including side effects of the medication, were felt to outweigh potential benefits. Although likely to render only modest urate-lowering effects, switching from an angiotensin-converting enzyme inhibitor to losartan carries a risk that seems to be sufficiently low in most patients to merit this change when feasible (for all recommendations for management of concurrent medications, see Table 8 and Supplementary Figure 5, available at http:// onlinelibrary.wiley.com/doi/10.1002/acr.24180/abstract).

\section{DISCUSSION}

This guideline reinforces many of the prior 2012 ACR Guidelines for the Management of Gout recommendations with updated literature and GRADE methodology, including incorporation of patient preferences and consideration of costs. The Voting Panel endorsed 42 recommendations overall, including 16 strong recommendations focused on ULT management (indications [ $n=3]$, initiation [ $n=6]$, titration and treat-to-target approach [ $n=2]$, approaches following ULT failure [ $\mathrm{n}=2]$ ), and flare management $(n=3)$.

Data from more recent RCTs comparing treat-to-target protocols versus usual care $(43,61)$ provide the basis for the strong recommendation to use a treat-to-target strategy with ULT that includes a plan to achieve and maintain an SU target of $<6 \mathrm{mg} / \mathrm{dl}$ to optimize patient outcomes. Findings from the evidence report resonated with the Patient Panel who concurred that their own SU levels correlated with related symptoms and changes in tophi. Patients on this panel articulated that $\mathrm{SU}$ assessments reinforced the importance of treatment adherence.

These guidelines reinforce the strategy of starting with lowdose ULT and titrating up to achieve the SU target. This strategy mitigates the risk of treatment-related adverse effects (e.g., hypersensitivity) as well as flare risk accompanying ULT initiation $(39,41)$. Lacking data on optimal titration regimens, the Voting Panel indicated that titration should be individualized, based on available provider resources (e.g., staff for augmented delivery of care), patient preferences, the timing of ambulatory encounters,

Table 8. Management of concurrent medications*

\begin{tabular}{|c|c|c|}
\hline Recommendation & $\begin{array}{c}\text { PICO } \\
\text { question }\end{array}$ & $\begin{array}{l}\text { Certainty of } \\
\text { evidence }\end{array}$ \\
\hline $\begin{array}{l}\text { For patients with gout, regardless of disease activity, we conditionally recommend } \\
\text { switching hydrochlorothiazide to an alternate antihypertensive when feasible. }\end{array}$ & 47 & Very low \\
\hline $\begin{array}{l}\text { We conditionally recommend against stopping low-dose aspirin (in those who are taking this medication for } \\
\text { appropriate indications). }\end{array}$ & 47 & Very low \\
\hline We conditionally recommend against adding or switching to fenofibrate. & 47 & Very low \\
\hline
\end{tabular}

Strongly recommend Conditionally recommend Strongly recommend against Conditionally recommend against

* PICO = population, intervention, comparator, outcomes. 
and antiinflammatory treatments. As described above, ULT titration should occur over weeks to months, not years. The 2012 ACR Guidelines for the Management of Gout recommended titration every 2-5 weeks (5). As noted in the ACR Clinical Quality Measures for Gout, SU concentrations should be checked after each dose titration (113). To limit the risk of ULT-related flares, these guidelines reinforce prior recommendations to use concurrent antiinflammatory prophylaxis for 3-6 months' duration, a shorter duration than advocated for in prior recommendations, but one that should be extended in the setting of frequent ongoing flares.

Breaking from prior $\mathrm{ACR}$ and European League Against Rheumatism (EULAR) guidelines, this guideline does not specify $\mathrm{SU}$ thresholds beyond $<6 \mathrm{mg} / \mathrm{dl}$ for patient subsets with more severe disease (e.g., those with tophi). This guideline is not intended to contradict or dispute prior recommendations. There is ample evidence that lower SU levels hasten the resolution of tophi $(23,114)$ and are associated with less frequent gout flares $(26,114)$, suggesting that lower SU thresholds may be preferable for patients with more burdensome gout. However, in contrast to a treatment strategy using an SU target of $<6 \mathrm{mg} / \mathrm{dl}$ as studied in clinical trials (43), there are no trial data to support lower specific thresholds for such patients.

In contrast to the 2012 ACR Guidelines for the Management of Gout (which did not consider treatment costs), this document firmly places allopurinol as the preferred first-line ULT for all patients, including those with CKD, due to the respective cost of each medication and potential CVD safety concerns that have recently emerged with febuxostat (72).

Under GRADE methodology, recommendations in these guidelines are supported by higher quality studies than the 2012 ACR Guidelines for the Management of Gout. This resulted in a more focused, less proscriptive document. Where certainty of data is less than moderate or high, conditional recommendations made herein are meant to highlight those decisions that would benefit from a shared patient-provider decision-making process. This would include areas such as diet, lifestyle, or concomitant medications that might affect SU levels, and for which the Patient Panel requested guidance. The Voting Panel aimed to provide guidance without implying any "patient-blaming" for the manifestations of gout given its strong genetic determinants.

Indications for ULT are expanded from the 2012 ACR Guidelines for the Management of Gout, but consistent with the 2016 update of the EULAR gout recommendations (10), to include individuals with evidence of radiographic damage attributable to gout (using any modality, regardless of subcutaneous tophi or flare frequency). This strong recommendation recognizes the various ways in which gout may present, and that joint damage is reflective of an active biologic process. Also added were conditional recommendations (which would warrant provider-patient shared medical decision-making discussion) for ULT use in patients with either infrequent flares (<2 flares/year) or a first flare with marked hyperuricemia (SU >9 mg/dl). Similar to the 2012 ACR Guidelines for the
Management of Gout, the Voting Panel advocated a "medicationin-pocket" strategy for gout flare management, which the Patient Panel reinforced as a preferred approach.

This updated guideline effort also identifies several areas that inform a research agenda for gout management. While data support an active treat-to-target strategy, a question remains as to what may be the optimal SU threshold for patients with more severe disease, in addition to questions about threshold values in specific populations of gout patients. Gout has differential impact on patients by sex, race, or by presence of other comorbidities. This guideline is limited in commenting on specific groups of gout patients, as more studies of specific patient cohorts are needed in order to make differential recommendations. Additional studies are needed to determine the safety of prolonged and profound treatmentrelated hypouricemia (e.g., SU $\leq 3 \mathrm{mg} / \mathrm{dl}$ ), an important knowledge gap given that epidemiologic studies have suggested an inverse association of SU concentration with select neurodegenerative disorders (115). While there are associations between SU and other comorbid conditions such as hypertension, CVD, and CKD (116), the benefit (or risk) of ULT in the absence of gout has yet to be established (117).

Gout has been characterized as a "curable disease" (118). As data continue to emerge supporting best practices in management, implementation of these recommendations will ideally lead to improved quality of care for patients with gout.

\section{ACKNOWLEDGMENTS}

We thank Theodore R. Fields, MD, FACP, Angelo L. Gaffo, $M D$, and Kenneth G. Saag, MD, for serving on the Expert Panel. We thank Jasvinder A. Singh for leading the Patient Panel meeting, as well as the patients who participated in this meeting: Lynn Brown, Jr., Douglas P. Davis, Larry Davis, Dextral L. Ely, Adam Paul Germek, Willie Earl Henton, James Edward Sims, and James Trucks. We thank N. Lawrence Edwards, MD, for his review of the manuscript. We thank Amit Aakash Shah, MD, MPH, for his assistance with the literature review. We thank the ACR staff, including Regina Parker for assistance in organizing the face-to-face meeting and coordinating the administrative aspects of the project, and Robin Lane for assistance in manuscript preparation. We thank Janet Joyce for help in developing the literature search strategy and performing the initial literature search, and Janet Waters for performing the update searches.

\section{AUTHOR CONTRIBUTIONS}

All authors were involved in drafting the article or revising it critically for important intellectual content, and all authors approved the final version to be submitted for publication. Dr. Neogi had full access to all of the data in the study and takes responsibility for the integrity of the data and the accuracy of the data analysis. 
Study conception and design. Fitzgerald, Dalbeth, Mikuls, Guyatt, Mount, Pillinger, Singh, P. Khanna, Kim, Sehra, Sharma, Toprover, Zeng, Turner, Neogi.

Acquisition of data. Fitzgerald, Dalbeth, Mikuls, Brignardello-Petersen, Khanna, Rosenthal, Bae, Danve, P. Khanna, Kim, Lenert, Poon, Qasim, Sehra, Sharma, Toprover, Turgunbaev, Zeng, Zhang, Neogi.

Analysis and interpretation of data. Fitzgerald, Dalbeth, Mikuls, Brignardello-Petersen, Guyatt, Abeles, Gelber, Harrold, D. Khanna, King, Levy, Libbey, Pillinger, Rosenthal, Singh, Sims, Smith, Wenger, Danve, P. Khanna, Poon, Qasim, Sehra, Sharma, Toprover, Turgunbaev, Zeng, Zhang, Neogi.

\section{REFERENCES}

1. Chen-Xu M, Yokose C, Rai SK, Pillinger MH, Choi HK. Contemporary prevalence of gout and hyperuricemia in the United States and decadal trends: the National Health and Nutrition Examination Survey, 2007-2016. Arthritis Rheumatol 2019;71:991-9.

2. Rashid N, Coburn BW, Wu YL, Cheetham TC, Curtis JR, Saag KG, et al. Modifiable factors associated with allopurinol adherence and outcomes among patients with gout in an integrated healthcare system. J Rheumatol 2015;42:504-12.

3. Sarawate CA, Brewer KK, Yang W, Patel PA, Schumacher HR, Saag KG, et al. Gout medication treatment patterns and adherence to standards of care from a managed care perspective. Mayo Clin Proc 2006;81:925-34.

4. Singh JA, Hodges JS, Toscano JP, Asch SM. Quality of care for gout in the US needs improvement. Arthritis Rheum 2007;57: 822-9.

5. Khanna D, Fitzgerald JD, Khanna PP, Bae S, Singh MK, Neogi T, et al. 2012 American College of Rheumatology guidelines for management of gout. Part 1. Systematic nonpharmacologic and pharmacologic therapeutic approaches to hyperuricemia. Arthritis Care Res (Hoboken) 2012;64:1431-46.

6. Khanna D, Khanna PP, Fitzgerald JD, Singh MK, Bae S, Neogi T, et al. 2012 American College of Rheumatology guidelines for management of gout. Part 2. Therapy and antiinflammatory prophylaxis of acute gouty arthritis. Arthritis Care Res (Hoboken) 2012;64:1447-61.

7. Romeijnders AC, Gorter KJ. Summary of the Dutch College of General Practitioners' "Gout” Standard. Ned Tijdschr Geneeskd 2002;146:309-13. In Dutch.

8. Zhang W, Doherty M, Bardin T, Pascual E, Barskova V, Conaghan P, et al. EULAR evidence based recommendations for gout. Part II. Management: report of a task force of the EULAR Standing Committee for International Clinical Studies Including Therapeutics (ESCISIT). Ann Rheum Dis 2006;65:1312-24.

9. Jordan KM, Cameron JS, Snaith M, Zhang W, Doherty M, Seck J, et al. British Society for Rheumatology and British Health Professionals in Rheumatology guideline for the management of gout. Rheumatology (Oxford) 2007;46:1372-4.

10. Richette P, Doherty M, Pascual E, Barskova V, Becce F, Castaneda-Sanabria J, et al. 2016 updated EULAR evidencebased recommendations for the management of gout. Ann Rheum Dis 2017;76:29-42.

11. Kuo CF, Grainge MJ, Mallen C, Zhang W, Doherty M. Rising burden of gout in the UK but continuing suboptimal management: a nationwide population study. Ann Rheum Dis 2015;74:661-7.

12. Briesacher BA, Andrade SE, Fouayzi H, Chan KA. Comparison of drug adherence rates among patients with seven different medical conditions. Pharmacotherapy 2008;28:437-43.

13. Duarte-Garcia A, Zamore R, Wong JB. The evidence basis for the American College of Rheumatology practice guidelines. JAMA Intern Med 2018;178:146-8.
14. McLean RM. The long and winding road to clinical guidelines on the diagnosis and management of gout. Ann Intern Med 2017;166: 73-4.

15. Guyatt GH, Oxman AD, Vist GE, Kunz R, Falck-Ytter $Y$, Alonso-Coello P, et al. GRADE: an emerging consensus on rating quality of evidence and strength of recommendations. BMJ 2008;336:924-6.

16. Hultcrantz M, Rind D, Akl EA, Treweek S, Mustafa RA, lorio A, et al. The GRADE Working Group clarifies the construct of certainty of evidence. J Clin Epidemiol 2017;87:4-13.

17. Alper BS, Oettgen P, Kunnamo I, lorio A, Ansari MT, Murad MH, et al. Defining certainty of net benefit: a GRADE concept paper. BMJ Open 2019;9:e027445.

18. De Lautour H, Dalbeth N, Taylor WJ. Outcome measures for gout clinical trials: a summary of progress. Curr Treatm Opt Rheumatol 2015;1:156-66.

19. Taylor WJ, Brown M, Aati O, Weatherall M, Dalbeth N. Do patient preferences for core outcome domains for chronic gout studies support the validity of composite response criteria? Arthritis Care Res (Hoboken) 2013;65:1259-64.

20. Schunemann HJ, Mustafa RA, Brozek J, Santesso N, Bossuyt PM, Steingart KR, et al. GRADE guidelines: 22. The GRADE approach for tests and strategies-from test accuracy to patient-important outcomes and recommendations. J Clin Epidemiol 2019;111:69-82.

21. Baraf HS, Becker MA, Gutierrez-Urena SR, Treadwell EL, Vazquez-Mellado J, Rehrig CD, et al. Tophus burden reduction with pegloticase: results from phase 3 randomized trials and open-label extension in patients with chronic gout refractory to conventional therapy. Arthritis Res Ther 2013;15:R137.

22. Strand V, Khanna D, Singh JA, Forsythe A, Edwards NL. Improved health-related quality of life and physical function in patients with refractory chronic gout following treatment with pegloticase: evidence from phase III randomized controlled trials. J Rheumatol 2012;39:1450-7.

23. Sundy JS, Baraf HS, Yood RA, Edwards NL, Gutierrez-Urena SR, Treadwell EL, et al. Efficacy and tolerability of pegloticase for the treatment of chronic gout in patients refractory to conventional treatment: two randomized controlled trials. JAMA 2011;306:711-20.

24. Tausche AK, Alten R, Dalbeth N, Kopicko J, Fung M, Adler S, et al. Lesinurad monotherapy in gout patients intolerant to a xanthine oxidase inhibitor: a 6-month phase 3 clinical trial and extension study. Rheumatology (Oxford) 2017;56:2170-8.

25. Dalbeth N, Jones G, Terkeltaub R, Khanna D, Kopicko J, Bhakta N, et al. Lesinurad, a selective uric acid reabsorption inhibitor, in combination with febuxostat in patients with tophaceous gout: findings of a phase III clinical trial. Arthritis Rheumatol 2017;69:1903-13.

26. Shoji A, Yamanaka $H$, Kamatani N. A retrospective study of the relationship between serum urate level and recurrent attacks of gouty arthritis: evidence for reduction of recurrent gouty arthritis with antihyperuricemic therapy. Arthritis Rheum 2004;51:321-5.

27. Dalbeth N, Saag KG, Palmer WE, Choi HK, Hunt B, MacDonald PA, et al. Effects of febuxostat in early gout: a randomized, double-blind, placebo-controlled study. Arthritis Rheumatol 2017;69:2386-95.

28. Levy GD, Rashid N, Niu F, Cheetham TC. Effect of urate-lowering therapies on renal disease progression in patients with hyperuricemia. J Rheumatol 2014;41:955-62.

29. Lu CC, Wu SK, Chen HY, Chung WS, Lee MC, Yeh CJ. Clinical characteristics of and relationship between metabolic components and renal function among patients with early-onset juvenile tophaceous gout. J Rheumatol 2014;41:1878-83.

30. Dalbeth N, House ME, Horne A, Taylor WJ. Reduced creatinine clearance is associated with early development of subcutaneous tophi in people with gout. BMC Musculoskelet Disord 2013;14:363. 
31. Kanji T, Gandhi M, Clase CM, Yang R. Urate lowering therapy to improve renal outcomes in patients with chronic kidney disease: systematic review and meta-analysis. BMC Nephrol 2015;16:58.

32. Campion EW, Glynn RJ, DeLabry LO. Asymptomatic hyperuricemia: risks and consequences in the Normative Aging Study. Am J Med 1987;82:421-6.

33. Goldfarb DS, MacDonald PA, Gunawardhana L, Chefo S, McLean L. Randomized controlled trial of febuxostat versus allopurinol or placebo in individuals with higher urinary uric acid excretion and calcium stones. Clin J Am Soc Nephrol 2013;8:1960-7.

34. Ettinger B, Tang A, Citron JT, Livermore B, Williams T. Randomized trial of allopurinol in the prevention of calcium oxalate calculi. N Engl J Med 1986;315:1386-9.

35. Liu P, Wang H, Zhang F, Chen $Y$, Wang D, Wang $Y$. The effects of allopurinol on the carotid intima-media thickness in patients with type 2 diabetes and asymptomatic hyperuricemia: a three-year randomized parallel-controlled study. Intern Med 2015;54:2129-37.

36. Kimura K, Hosoya T, Uchida S, Inaba M, Makino H, Maruyama $S$, et al. Febuxostat therapy for patients with stage 3 CKD and asymptomatic hyperuricemia: a randomized trial. Am J Kidney Dis 2018;72:798-810.

37. Perez-Ruiz F, Herrero-Beites AM, Carmona L. A two-stage approach to the treatment of hyperuricemia in gout: the "dirty dish" hypothesis. Arthritis Rheum 2011;63:4002-6.

38. Zyloprim (allopurinol) product information. East Brunswick (NJ): Casper Pharma; 2018. URL: https://www.accessdata.fda.gov/ drugsatfda_docs/label/2018/016084s044lbl.pdf.

39. Stamp LK, Taylor WJ, Jones PB, Dockerty JL, Drake J, Frampton $\mathrm{C}$, et al. Starting dose is a risk factor for allopurinol hypersensitivity syndrome: a proposed safe starting dose of allopurinol. Arthritis Rheum 2012;64:2529-36.

40. Stamp LK, Chapman PT, Barclay ML, Horne A, Frampton C, Tan $P$, et al. A randomised controlled trial of the efficacy and safety of allopurinol dose escalation to achieve target serum urate in people with gout. Ann Rheum Dis 2017;76:1522-8.

41. Yamanaka H, Tamaki S, Ide Y, Kim H, Inoue K, Sugimoto M, et al. Stepwise dose increase of febuxostat is comparable with colchicine prophylaxis for the prevention of gout flares during the initial phase of urate-lowering therapy: results from FORTUNE-1, a prospective, multicentre randomised study. Ann Rheum Dis 2018;77:270-6.

42. Perez-Ruiz F, Alonso-Ruiz A, Calabozo M, Herrero-Beites A, Garcia-Erauskin G, Ruiz-Lucea E. Efficacy of allopurinol and benzbromarone for the control of hyperuricaemia: a pathogenic approach to the treatment of primary chronic gout. Ann Rheum Dis 1998;57:545-9.

43. Doherty M, Jenkins W, Richardson H, Sarmanova A, Abhishek A, Ashton D, et al. Efficacy and cost-effectiveness of nurse-led care involving education and engagement of patients and a treat-to-target urate-lowering strategy versus usual care for gout: a randomised controlled trial. Lancet 2018;392:1403-12.

44. Wright DF, Duffull SB, Merriman TR, Dalbeth N, Barclay ML, Stamp LK. Predicting allopurinol response in patients with gout. Br J Clin Pharmacol 2016;81:277-89.

45. Stamp LK, Chapman PT, Barclay M, Horne A, Frampton C, Tan $P$, et al. Allopurinol dose escalation to achieve serum urate below $6 \mathrm{mg} / \mathrm{dL}$ : an open-label extension study. Ann Rheum Dis 2017;76:2065-70.

46. Borstad GC, Bryant LR, Abel MP, Scroggie DA, Harris MD, Alloway JA. Colchicine for prophylaxis of acute flares when initiating allopurinol for chronic gouty arthritis. J Rheumatol 2004;31:2429-32.

47. Mitha E, Schumacher HR, Fouche L, Luo SF, Weinstein SP, Yancopoulos GD, et al. Rilonacept for gout flare prevention during initiation of uric acid-lowering therapy: results from the PRE-
SURGE-2 international, phase 3, randomized, placebo-controlled trial. Rheumatology (Oxford) 2013;52:1285-92.

48. Paulus HE, Schlosstein LH, Godfrey RG, Klinenberg JR, Bluestone R. Prophylactic colchicine therapy of intercritical gout: a placebocontrolled study of probenecid-treated patients. Arthritis Rheum 1974;17:609-14.

49. Poiley J, Steinberg AS, Choi YJ, Davis CS, Martin RL, McWherter CA, et al. A randomized, double-blind, active- and placebo-controlled efficacy and safety study of arhalofenate for reducing flare in patients with gout. Arthritis Rheumatol 2016;68:2027-34.

50. Schlesinger N, Mysler E, Lin HY, De Meulemeester M, Rovensky $\mathrm{J}$, Arulmani $\mathrm{U}$, et al. Canakinumab reduces the risk of acute gouty arthritis flares during initiation of allopurinol treatment: results of a double-blind, randomised study. Ann Rheum Dis 2011;70:1264-71.

51. Schumacher HR Jr, Evans RR, Saag KG, Clower J, Jennings W, Weinstein SP, et al. Rilonacept (interleukin-1 trap) for prevention of gout flares during initiation of uric acid-lowering therapy: results from a phase III randomized, double-blind, placebo-controlled, confirmatory efficacy study. Arthritis Care Res (Hoboken) 2012;64: 1462-70.

52. Sundy JS, Schumacher HR, Kivitz A, Weinstein SP, Wu R, King-Davis $S$, et al. Rilonacept for gout flare prevention in patients receiving uric acid-lowering therapy: results of RESURGE, a phase III, international safety study. J Rheumatol 2014;41:1703-11.

53. Solomon DH, Liu CC, Kuo IH, Zak A, Kim SC. Effects of colchicine on risk of cardiovascular events and mortality among patients with gout: a cohort study using electronic medical records linked with Medicare claims. Ann Rheum Dis 2016;75:1674-9.

54. Yu J, Qiu Q, Liang L, Yang X, Xu H. Prophylaxis of acute flares when initiating febuxostat for chronic gouty arthritis in a real-world clinical setting. Mod Rheumatol 2018;28:339-44.

55. Becker MA, Schumacher HR Jr, Wortmann RL, MacDonald PA, Eustace D, Palo WA, et al. Febuxostat compared with allopurinol in patients with hyperuricemia and gout. $\mathrm{N}$ Engl $\mathrm{J}$ Med 2005;353:2450-61.

56. Schumacher HR Jr, Becker MA, Wortmann RL, Macdonald PA, Hunt B, Streit J, et al. Effects of febuxostat versus allopurinol and placebo in reducing serum urate in subjects with hyperuricemia and gout: a 28-week, phase III, randomized, double-blind, parallelgroup trial. Arthritis Rheum 2008;59:1540-8.

57. Hill EM, Sky K, Sit M, Collamer A, Higgs J. Does starting allopurinol prolong acute treated gout? A randomized clinical trial. J Clin Rheumatol 2015;21:120-5.

58. Taylor TH, Mecchella JN, Larson RJ, Kerin KD, Mackenzie TA. Initiation of allopurinol at first medical contact for acute attacks of gout: a randomized clinical trial. Am J Med 2012;125:1126-34.e7.

59. Feng $X, L i$ Y, Gao W. Significance of the initiation time of uratelowering therapy in gout patients: a retrospective research. Joint Bone Spine 2015;82:428-31.

60. Goldfien R, Pressman A, Jacobson A, Ng M, Avins A. A pharmaciststaffed, virtual gout management clinic for achieving target serum uric acid levels: a randomized clinical trial. Perm J 2016;20:15-234.

61. Mikuls TR, Cheetham TC, Levy GD, Rashid N, Kerimian A, Low KJ, et al. Adherence and outcomes with urate-lowering therapy: a siterandomized trial. Am J Med 2019;132:354-61.

62. Phillips LS, Branch WT, Cook CB, Doyle JP, El-Kebbi IM, Gallina DL, et al. Clinical inertia. Ann Intern Med 2001;135:825-34.

63. De Lautour H, Taylor WJ, Adebajo A, Alten R, Burgos-Vargas R, Chapman P, et al. Development of preliminary remission criteria for gout using Delphi and 1000Minds consensus exercises. Arthritis Care Res (Hoboken) 2016;68:667-72.

64. Hung SI, Chung WH, Liou LB, Chu CC, Lin M, Huang HP, et al. $H\left\llcorner A-B^{\star} 5801\right.$ allele as a genetic marker for severe cutaneous ad- 
verse reactions caused by allopurinol. Proc Natl Acad Sci U S A 2005;102:4134-9.

65. Tassaneeyakul W, Jantararoungtong T, Chen P, Lin PY, Tiamkao S, Khunarkornsiri U, et al. Strong association between HLA-B*5801 and allopurinol-induced Stevens-Johnson syndrome and toxic epidermal necrolysis in a Thai population. Pharmacogenet Genomics 2009; 19:704-9.

66. Gonzalez-Galarza FF, Takeshita LY, Santos EJ, Kempson F, Maia $\mathrm{MH}$, da Silva AL, et al. Allele frequency net 2015 update: new features for HLA epitopes, KIR and disease and HLA adverse drug reaction associations. Nucleic Acids Res 2015;43(Database issue):D784-8.

67. Jutkowitz E, Dubreuil M, Lu N, Kuntz KM, Choi HK. The costeffectiveness of HLA-B*5801 screening to guide initial uratelowering therapy for gout in the United States. Semin Arthritis Rheum 2017;46:594-600.

68. Keller SF, Lu N, Blumenthal KG, Rai SK, Yokose C, Choi JW, et al. Racial/ethnic variation and risk factors for allopurinol-associated severe cutaneous adverse reactions: a cohort study. Ann Rheum Dis 2018;77:1187-93.

69. Fam AG, Dunne SM, lazzetta J, Paton TW. Efficacy and safety of desensitization to allopurinol following cutaneous reactions. Arthritis Rheum 2001;44:231-8.

70. Soares J, Caiado J, Lopes A, Pereira BM. Allopurinol desensitization: a fast or slow protocol? J Investig Allergol Clin Immunol 2015;25:295-7.

71. US Food and Drug Administration. FDA adds boxed warning for increased risk of death with gout medicine Uloric (febuxostat). URL: https://www.fda.gov/drugs/drug-safety-and-availability/fda-addsboxed-warning-increased-risk-death-gout-medicine-uloric-febux ostat.

72. White WB, Saag KG, Becker MA, Borer JS, Gorelick PB, Whelton $A$, et al. Cardiovascular safety of febuxostat or allopurinol in patients with gout. N Engl J Med 2018;378:1200-10.

73. Zhang M, Solomon DH, Desai RJ, Kang EH, Liu J, Neogi T, et al. Assessment of cardiovascular risk in older patients with gout initiating febuxostat versus allopurinol. Circulation 2018;138: 1116-26.

74. Foody J, Turpin RS, Tidwell BA, Lawrence D, Schulman KL. Major cardiovascular events in patients with gout and associated cardiovascular disease or heart failure and chronic kidney disease initiating a xanthine oxidase inhibitor. Am Health Drug Benefits 2017;10:393-401.

75. Perez-Ruiz F, Hernandez-Baldizon S, Herrero-Beites AM, Gonzalez-Gay MA. Risk factors associated with renal lithiasis during uricosuric treatment of hyperuricemia in patients with gout. Arthritis Care Res (Hoboken) 2010;62:1299-305.

76. Saag KG, Fitz-Patrick D, Kopicko J, Fung M, Bhakta N, Adler S, et al. Lesinurad combined with allopurinol: a randomized, doubleblind, placebo-controlled study in gout patients with an inadequate response to standard-of-care allopurinol (a US-based study). Arthritis Rheumatol 2017;69:203-12.

77. Becker MA, Baraf HS, Yood RA, Dillon A, Vazquez-Mellado J, Ottery $\mathrm{FD}$, et al. Long-term safety of pegloticase in chronic gout refractory to conventional treatment. Ann Rheum Dis 2013;72:1469-74.

78. Solomon DH, Bitton A, Katz JN, Radner H, Brown EM, Fraenkel L. Treat to target in rheumatoid arthritis: fact, fiction, or hypothesis? [review]. Arthritis Rheumatol 2014;66:775-82.

79. Alloway JA, Moriarty MJ, Hoogland YT, Nashel DJ. Comparison of triamcinolone acetonide with indomethacin in the treatment of acute gouty arthritis. J Rheumatol 1993;20:111-3.

80. Siegel LB, Alloway JA, Nashel DJ. Comparison of adrenocorticotropic hormone and triamcinolone acetonide in the treatment of acute gouty arthritis. J Rheumatol 1994;21:1325-7.
81. Axelrod D, Preston S. Comparison of parenteral adrenocorticotropic hormone with oral indomethacin in the treatment of acute gout. Arthritis Rheum 1988;31:803-5.

82. Man CY, Cheung IT, Cameron PA, Rainer TH. Comparison of oral prednisolone/paracetamol and oral indomethacin/paracetamol combination therapy in the treatment of acute gout-like arthritis: a double-blind, randomized, controlled trial. Ann Emerg Med 2007:49:670-7.

83. Janssens $H J$, Janssen $M$, van de Lisdonk $E H$, van Riel $P L$, van Weel C. Use of oral prednisolone or naproxen for the treatment of gout arthritis: a double-blind, randomised equivalence trial. Lancet 2008;371:1854-60.

84. So A, De Meulemeester M, Pikhlak A, Yücel AE, Richard D, Murphy $V$, et al. Canakinumab for the treatment of acute flares in difficult-totreat gouty arthritis: results of a multicenter, phase II, dose-ranging study. Arthritis Rheum 2010;62:3064-76.

85. Schumacher HR, Berger MF, Li-Yu J, Perez-Ruiz F, Burgos-Vargas $\mathrm{R}$, Li C. Efficacy and tolerability of celecoxib in the treatment of acute gouty arthritis: a randomized controlled trial. J Rheumatol 2012;39:1859-66.

86. Terkeltaub RA, Schumacher HR, Carter JD, Baraf HS, Evans RR, Wang J, et al. Rilonacept in the treatment of acute gouty arthritis: a randomized, controlled clinical trial using indomethacin as the active comparator. Arthritis Res Ther 2013;15:R25.

87. Zhang YK, Yang H, Zhang JY, Song LJ, Fan YC. Comparison of intramuscular compound betamethasone and oral diclofenac sodium in the treatment of acute attacks of gout. Int $\mathrm{J}$ Clin Pract 2014;68:633-8.

88. Hirsch JD, Gnanasakthy A, Lale R, Choi K, Sarkin AJ. Efficacy of canakinumab vs. triamcinolone acetonide according to multiple gouty arthritis-related health outcomes measures. Int $\mathrm{J}$ Clin Pract 2014;68:1503-7.

89. Schlesinger N, Alten RE, Bardin T, Schumacher HR, Bloch M, Gimona A, et al. Canakinumab for acute gouty arthritis in patients with limited treatment options: results from two randomised, multicentre, active-controlled, double-blind trials and their initial extensions. Ann Rheum Dis 2012;71:1839-48.

90. Schlesinger N, De Meulemeester M, Pikhlak A, Yucel AE, Richard D, Murphy V, et al. Canakinumab relieves symptoms of acute flares and improves health-related quality of life in patients with difficult-to-treat gouty arthritis by suppressing inflammation: results of a randomized, dose-ranging study. Arthritis Res Ther 2011;13:R53.

91. Schlesinger N, Detry MA, Holland BK, Baker DG, Beutler AM, Rull $M$, et al. Local ice therapy during bouts of acute gouty arthritis. J Rheumatol 2002;29:331-4.

92. Major TJ, Topless RK, Dalbeth N, Merriman TR. Evaluation of the diet wide contribution to serum urate levels: meta-analysis of population-based cohorts. BMJ 2018;363:k3951.

93. Kottgen A, Albrecht E, Teumer A, Vitart V, Krumsiek J, Hundertmark $\mathrm{C}$, et al. Genome-wide association analyses identify 18 new loci associated with serum urate concentrations. Nat Genet 2013;45:145-54.

94. Spencer K, Carr A, Doherty M. Patient and provider barriers to effective management of gout in general practice: a qualitative study. Ann Rheum Dis 2012;71:1490-5.

95. Ralston SH, Capell HA, Sturrock RD. Alcohol and response to treatment of gout. Br Med J (Clin Res Ed) 1988;296:1641-2.

96. Gibson T, Kilbourn K, Horner I, Simmonds HA. Mechanism and treatment of hypertriglyceridaemia in gout. Ann Rheum Dis 1979;38: $31-5$.

97. Neogi T, Chen C, Niu J, Chaisson C, Hunter DJ, Zhang Y. Alcohol quantity and type on risk of recurrent gout attacks: an internetbased case-crossover study. Am J Med 2014;127:311-8. 
98. Zhang Y, Chen C, Choi H, Chaisson C, Hunter D, Niu J, et al. Purine-rich foods intake and recurrent gout attacks. Ann Rheum Dis 2012;71:1448-53.

99. Holland R, McGill NW. Comprehensive dietary education in treated gout patients does not further improve serum urate. Intern Med $J$ 2015;45:189-94.

100. Stirpe F, Della Corte E, Bonetti E, Abbondanza A, Abbati A, De Stefano F. Fructose-induced hyperuricaemia. Lancet 1970;2: 1310-1.

101. Choi JW, Ford ES, Gao X, Choi HK. Sugar-sweetened soft drinks, diet soft drinks, and serum uric acid level: the Third National Health and Nutrition Examination Survey. Arthritis Rheum 2008;59:109-16.

102. Choi HK, Willett W, Curhan G. Fructose-rich beverages and risk of gout in women. JAMA 2010;304:2270-8.

103. Sacks FM, Svetkey LP, Vollmer WM, Appel LJ, Bray GA, Harsha D, et al, for the DASH-Sodium Collaborative Research Group. Effects on blood pressure of reduced dietary sodium and the Dietary Approaches to Stop Hypertension (DASH) diet. N Engl J Med 2001;344:3-10.

104. Nielsen SM, Bartels EM, Henriksen M, Waehrens EE, Gudbergsen $H$, Bliddal $H$, et al. Weight loss for overweight and obese individuals with gout: a systematic review of longitudinal studies. Ann Rheum Dis 2017;76:1870-82.

105. Nguyen UD, Zhang Y, Louie-Gao Q, Niu J, Felson DT, LaValley MP, et al. Obesity paradox in recurrent attacks of gout in observational studies: clarification and remedy. Arthritis Care Res (Hoboken) 2017;69:561-6.

106. Dalbeth N, Chen P, White M, Gamble GD, Barratt-Boyes C, Gow $\mathrm{PJ}$, et al. Impact of bariatric surgery on serum urate targets in people with morbid obesity and diabetes: a prospective longitudinal study. Ann Rheum Dis 2014;73:797-802.

107. Romero-Talamas H, Daigle CR, Aminian A, Corcelles R, Brethauer SA, Schauer PR. The effect of bariatric surgery on gout: a comparative study. Surg Obes Relat Dis 2014;10:1161-5.

108. Dessein PH, Shipton EA, Stanwix AE, Joffe BI, Ramokgadi J. Beneficial effects of weight loss associated with moderate calorie/carbohydrate restriction, and increased proportional intake of protein and unsaturated fat on serum urate and lipoprotein levels in gout: a pilot study. Ann Rheum Dis 2000;59:539-43.

109. Stamp LK, O'Donnell JL, Frampton C, Drake JM, Zhang M, Chapman PT. Clinically insignificant effect of supplemental vitamin $\mathrm{C}$ on serum urate in patients with gout: a pilot randomized controlled trial. Arthritis Rheum 2013;65:1636-42.

110. Daskalopoulou SS, Tzovaras V, Mikhailidis DP, Elisaf M. Effect on serum uric acid levels of drugs prescribed for indications other than treating hyperuricaemia. Curr Pharm Des 2005;11:4161-75.

111. Miao Y, Ottenbros SA, Laverman GD, Brenner BM, Cooper ME, Parving $\mathrm{HH}$, et al. Effect of a reduction in uric acid on renal outcomes during losartan treatment: a post hoc analysis of the reduction of endpoints in non-insulin-dependent diabetes mellitus with the Angiotensin II Antagonist Losartan Trial. Hypertension 2011;58:2-7.

112. Waldman B, Ansquer JC, Sullivan DR, Jenkins AJ, McGill N, Buizen $L$, et al. Effect of fenofibrate on uric acid and gout in type 2 diabetes: a post-hoc analysis of the randomised, controlled FIELD study. Lancet Diabetes Endocrinol 2018;6:310-8.

113. FitzGerald JD, Mikuls TR, Neogi T, Singh JA, Robbins M, Khanna PP, et al. Development of the American College of Rheumatology electronic clinical quality measures for gout. Arthritis Care Res (Hoboken) 2018;70:659-71.

114. Perez-Ruiz F, Calabozo M, Pijoan Jl, Herrero-Beites AM, Ruibal A. Effect of urate-lowering therapy on the velocity of size reduction of tophi in chronic gout. Arthritis Rheum 2002;47:356-60.

115. Khan AA, Quinn TJ, Hewitt J, Fan Y, Dawson J. Serum uric acid level and association with cognitive impairment and dementia: systematic review and meta-analysis. Age (Dordr) 2016;38:16.

116. Levy G, Shi JM, Cheetham TC, Rashid N. Urate-lowering therapy in moderate to severe chronic kidney disease. Perm J 2018;22: 17-142.

117. Abeles AM, Pillinger MH. Gout and cardiovascular disease: crystallized confusion. Curr Opin Rheumatol 2019;31:118-24.

118. Doherty M, Jansen TL, Nuki G, Pascual E, Perez-Ruiz F, Punzi L, et al. Gout: why is this curable disease so seldom cured? Ann Rheum Dis 2012;71:1765-70. 